\title{
STUDY OF IN VIVO PHARMACOKINETIC DRUG INTERACTIONS OF CURCUMIN ON TACRINE
}

\author{
RAJASEKHAR REDDY ALAVALA, ${ }^{1,2}$, PRATHUSHA KATAHALA ${ }^{1}$, GANAPATHI THIPPARAPU ${ }^{1}$, \\ UMASANKAR KULANDAIVELU ${ }^{1,2}$, SHIREESHA BOYAPATI ${ }^{3 *}$, BHAGAVAN RAJU MANTRIPRAGADA ${ }^{4}$
}

\begin{abstract}
${ }^{1}$ Department of Pharmaceutical Chemistry, Vaagdevi College of Pharmacy, Ramnagar, Hanamkonda, Warangal, Telangana, India. ${ }^{2}$ Department of Pharmaceutical Chemistry, K L College of Pharmacy, KL University, Vaddeswaram, Guntur, Andhra Pradesh, India. ${ }^{3}$ Department of Pharmaceutical Chemistry, University College of Science, Telangana University, Dichpally, Nizamabad, Telangana, India. ${ }^{4}$ Department of Pharmaceutical Chemistry, Venkateswara College of Pharmacy, Madhapur, Hyderabad, Telangana, India. Email:sirimedchem@gmail.com
\end{abstract}

Received: 21 April 2018, Revised and Accepted: 31 May 2018

ABSTRACT

Objective: Tacrine is a potent acetylcholine esterase inhibitor (AChEI), and curcumin has been recently proven to possess AChEI, amyloid $\beta$ aggregation inhibitory activity in addition to its diverse pharmacodynamic nature. Tacrine undergoes biological transformation by cytochrome P450 (CYP 1A2) to a hydroxy metabolite, which is hepatotoxic. Curcumin is known for its inhibitory nature for various metabolic enzymes along with CYP1A2. The present study was undertaken to evaluate the influence of curcumin on the disposition kinetics of tacrine and to assess its impact on dosage regimen.

Methods: It was hypothesized that the simultaneous administration of curcumin and tacrine can minimize the toxicity along with increased absorption of tacrine and curcumin into the biological system during the treatment of Alzheimer's patients.

Results: Hence, an attempt was made to develop a simple, precise, accurate, and cost-effective reversed-phase high-performance liquid chromatography method for simultaneous determination of curcumin and tacrine and also to estimate the effect of curcumin on absorption of tacrine, in rat plasma.

Conclusion: Concomitant administration of curcumin with tacrine improved the parameters such as $\mathrm{C}_{\max }$ and AUC, which indicates that the curcumin would improve the absorption of tacrine.

Key words: Alzheimer's disease, Curcumin, Tacrine, Pharmacokinetic studies, Reversed-phase high-performance liquid chromatography.

(C) 2018 The Authors. Published by Innovare Academic Sciences Pvt Ltd. This is an open access article under the CC BY license (http://creativecommons. org/licenses/by/4. 0/) DOI: http://dx.doi.org/10.22159/ajpcr.2018.v11i9.26831

\section{INTRODUCTION}

Tacrine (1,2,3,4-tetrahydroacridin-9-amine; Cognex; THA) was treated as the first acetylcholine esterase inhibitor (AChEI) approved to use in the treatment of Alzheimer's Disease (AD) by the Food and Drug Administration in 1993, which was most potent and clinically effective AChEI. It was shown significant effect as a palliative treatment for the AD symptoms. It possesses a very decent pharmacokinetic properties (e.g., penetration through blood-brain barrier and AChEI activity on nM scale) [1]. Shortly after its approval, it was retracted from the pharmaceutical market for its poor selectivity toward AChE that resulted in a number of serious side effects. The potential adverse effect of THA is liver damage, which was indicated by increased of the alanine aminotransferase levels. THA was prone to metabolism by cytochrome $\mathrm{P}_{450}$ (CYP 1A2) and resulted the different hydroxy analogs that are responsible for its hepatotoxicity [2]

Curcumin (diferuloylmethane) is a hydrophobic polyphenol isolated from the rhizomes of Curcuma longa L. (Turmeric). Mostly, turmeric is used as a dietary spice in most of the Asian countries. Moreover, the literature of traditional medicine of India and China has described that turmeric was used for the treatment of a range of diseases. Turmeric beneficial effects were attributed to the curcumin as the main phytochemical constituent [3]. Despite curcumin beneficial effects, its promotion to the clinical trials was hampered due to its poor ADME properties. Curcumin was revealed to possess poor absorption, limited tissue distribution, and rapid metabolism in the liver and intestine that severely curtails its bioavailability [4-7]. On the other hand, curcumin improves the bioavailability of other drugs by inhibiting nonspecific drug metabolizing enzymes (CYP450 isozymes) [8]. Similarly, curcumin suppresses drug metabolizing enzymes (CYP1A1, 1A2, 2B1, and 3A4) in the liver as well as decreases the inducing changes in these enzymes by phenobarbitone and benzo(a)pyran in the liver, lung, and stomach, hence increasing the pharmacokinetic parameters such as maximum absorption concentration ( $\mathrm{Cmax}$ ) and area under the plasma concentration-time curve (AUC) of the substrate compound [9-11]. Curcumin has also shown hepatoprotective [12], nephroprotective [13], AChE inhibitory [14], and amyloid $\beta$ protein aggregation inhibitory activities in vivo [15].

With this background, the present study was initiated to evaluate the influence of curcumin on disposition kinetics of tacrine and to assess its impact on dosage regimen. It was hypothesized that the simultaneous administration of curcumin and tacrine can minimize the toxicity along with increased absorption of tacrine and curcumin into the biological system during the treatment of Alzheimer's patients. Hence, an attempt was made to develop a simple, precise, accurate, and cost-effective reversed-phase high-performance liquid chromatography (RP-HPLC) method for simultaneous determination of curcumin and tacrine and also to estimate the levels of curcumin on the absorption of tacrine and vice versa.

\section{METHODS}

Chemicals and reagents

Reference standards of curcumin, tacrine, and tenofovir (IS) with purity of $>97 \%$ were purchased from the Sigma-Aldrich Laboratories (Bengaluru, India). HPLC grade acetonitrile, water, glacial acetic acid, and AR grade of Sodium citrate and diethyl ether were purchased from SD Fine Chemicals (Mumbai, India). 


\section{Instruments}

The following instruments were used: Shimadzu ultraviolet (UV-1800) double-beam UV-visible spectrophotometer, Shimadzu SPD 10A HPLC system, Remi RM 12C Centrifuge, Blue Star Refrigerator, sonicator (Hwashin Technology, Korea), Remi CM101 cyclomixer, micropipettes (10-100 $\mathrm{LL}$ and 100-1000 $\mu \mathrm{L})$, Eppendorf tubes, and heparinized capillaries (Tarsons Products Pvt. Ltd., Kolkata, India).

\section{Experimental animals}

Healthy male albino rats (250-300 g) were used in this study in accordance with institutional guidelines and approval of local ethics authorities (1047/ac/07/CPCSEA, Dated 24-04-2007). These were purchased from Teena BioLabs, Hyderabad, Telangana. The animals were maintained on a $12 \mathrm{~h}$ light-dark cycle (light on from 8:00 to $20: 00 \mathrm{~h}$ ) at an ambient temperature of $25 \pm 2^{\circ} \mathrm{C}$ and $50 \pm 15 \%$ relative humidity. Rats were fed with a commercial pellet diet (Hindustan lever Pvt. Ltd., Mumbai, India) and water ad libitum. They were fasted overnight before the experiment, and during the experiment, the food is withdrawn but not the water.

\section{HPLC analysis}

The HPLC system consisted of a Shimadzu class $10 \mathrm{~A}$ series with a $50 \mu \mathrm{L}$ sample loop coupled to SPD 10AVP UV-visible detector set to $241 \mathrm{~nm}$ and a computer system for data acquisition (Class LC-10AT series version 5.03, Shimadzu) was used. The separation was achieved using a reversed phase $\mathrm{C}-18$ column $(4.6 \mathrm{~mm} \times 250 \mathrm{~mm}$, particle size $5 \mu \mathrm{m}$ ). Mobile phase consisting of acetonitrile: Water containing $0.1 \%$ glacial acetic acid: (70:30\% v/v) was employed at a flow rate of $1.0 \mathrm{~mL} / \mathrm{min}$.

\section{Preparation of standard solutions}

Primary stock solutions of tenofovir (Internal standard) were prepared at a concentration of $1 \mathrm{mg} / \mathrm{mL}$ using acetonitrile as a solvent and stored at $-20^{\circ} \mathrm{C}$.

\section{Standard graph procedure}

Primary stock solution of tenofovir was diluted with acetonitrile to obtain the working solution of $100 \mu \mathrm{g} / \mathrm{mL}$ concentration. To $100 \mu \mathrm{L}$ of plasma samples, $20 \mu \mathrm{L}$ of internal standard from $100 \mu \mathrm{g} / \mathrm{mL}$ of working solution was added to obtain $20 \mu \mathrm{g} / \mathrm{mL}$ final concentration, and $20 \mu \mathrm{L}$ of tacrine was added from each concentration to obtain final concentrations of $200,300,400,1500$, and $4000 \mathrm{ng} / \mathrm{mL}$ of tacrine. To $100 \mu \mathrm{L}$ of plasma samples, $20 \mu \mathrm{L}$ of internal standard from $100 \mu \mathrm{g} / \mathrm{mL}$ of working solution was added to obtain $20 \mu \mathrm{g} / \mathrm{mL}$ final concentration, and $20 \mu \mathrm{L}$ of curcumin was added from each concentration to obtain final concentrations of 1000, 2000,3000, 4000, and $5000 \mathrm{ng} / \mathrm{mL}$ of curcumin. The resultant solution was mixed for 2 min on cyclomixer at room temperature, and $400 \mu \mathrm{L}$ of acetonitrile was added and centrifuged at $4000 \mathrm{rpm}$ for $10 \mathrm{~min}$. The supernatant was separated which is called Supernatant I and $400 \mu \mathrm{L}$ of acetonitrile was added to residue and the resultant solution was mixed again for $2 \mathrm{~min}$ on cyclomixer at room temperature and centrifuged at $4000 \mathrm{rpm}$ for 20 min, and then Supernatant II was added to the Supernatant I. The pooled Supernatants I and II were collected and kept for evaporation to dryness on water bath, the residue was dissolved in $200 \mu \mathrm{L}$ of acetonitrile, and after filtration through $0.2 \mu \mathrm{m}$ syringe filter, $20 \mu \mathrm{L}$ of the solution was spiked for the HPLC analysis [16].

The peak area of the drugs and internal standard was determined, and the peak area ratio was calculated using the formula

Peak area ratio $=$ peak area of drug/peak area of internal standard

Graph is plotted by taking peak area ratio on Y-axis and concentration on X-axis. The standard graph was considered to be significant when the $r^{2}$ value is $\geq 0.99$.

\section{Extraction procedures (LLE)}

$100 \mu \mathrm{L}$ of the collected plasma samples were taken, to it $20 \mu \mathrm{L}$ of $1 \mathrm{mg} / \mathrm{mL}$ tenofovir and $400 \mu \mathrm{L}$ of acetonitrile was added, the resulting solution was vortexed for 5 min on cyclomixer and centrifuged at $2000 \mathrm{rpm}$ for $10 \mathrm{~min}$, and the supernatant layer was separated. The residue was added with another $400 \mu \mathrm{L}$ of acetonitrile and mixed again for $5 \mathrm{~min}$ on cyclomixer and centrifuged at $2000 \mathrm{rpm}$ for $10 \mathrm{~min}$. Then, supernatant was separated and added to previously separated supernatant layer. The collected supernatant liquid was evaporated to dryness on water bath, the obtained residue was dissolved in $100 \mu \mathrm{L}$ of mobile phase and filtered through $0.2 \mu \mathrm{m}$ syringe filter, and $20 \mu \mathrm{L}$ of the filtered solution was used for the HPLC analysis [17-21].

\section{HPLC method validation}

The developed analytical method was validated by the following ICH guidelines for selectivity, precision, accuracy, linearity, limit of detection (LOD), lower limit of quantitation (LOQ), robustness, and ruggedness [22,23].

\section{Pharmacokinetic study of tacrine and curcumin Grouping of animals}

Albino rats (4) were grouped as follows: Group I: Control (5\% gum acacia $10 \mathrm{~mL} / \mathrm{kg}$ per oral), Group II: Curcumin $(80 \mathrm{mg} / \mathrm{kg}$ for single day), Group III: Tacrine ( $4 \mathrm{mg} / \mathrm{kg}$ for single day), and Group IV: Tacrine and curcumin (tacrine $4 \mathrm{mg} / \mathrm{kg}$ and curcumin $80 \mathrm{mg} / \mathrm{kg}$ for single day).

Albino rats were administered with drugs as mentioned above. Blood samples $(0.3 \mathrm{~mL})$ were collected through retro-orbital plexus under mild ether anesthesia at a time period of $0,1,2,3,4,6$, and $12 \mathrm{~h}$ following drug administration using sodium citrate $(3.8 \%)$ as an anticoagulant. Blood samples were immediately centrifuged at $2000 \mathrm{rpm}$ for $10 \mathrm{~min}$, and the plasma was separated and stored at $-20^{\circ} \mathrm{C}$ until analysis. At the time of analysis, the stored plasma was used for extraction as described above.

After determining the concentration of tacrine and curcumin in extracted plasma, the graph was plotted by taking average concentration values of tacrine and curcumin in plasma samples on Y-axis and corresponding time in hours on X-axis. Various pharmacokinetic parameters such as $\mathrm{C}_{\text {max }}, \mathrm{T}_{\text {max }}$, AUC, MRT, $\mathrm{t}_{1 / 2}$ and $\mathrm{KE}, \mathrm{V}_{\mathrm{d}}$, and $\mathrm{Cl}$ were calculated by applying non-compartment model using Kinetica 5.0 software [24,25].

\section{RESULTS AND DISCUSSION}

\section{Method development for evaluation of tacrine and curcumin}

The absorbance of tacrine and curcumin was scanned entire UV range (i.e., 200-400 $\mathrm{nm}$ ) using a Shimadzu double-beam UV-visible spectrophotometer (UV 1800), and the maximum absorbance ( $\lambda$ max) was found at of $241 \mathrm{~nm}$ wavelength. Therefore, the wavelength of $241 \mathrm{~nm}$ was chosen for the present study. Acetonitrile: Water containing $0.1 \%$ glacial acetic acid: $70: 30 \% \mathrm{v} / \mathrm{v}$ was used as the mobile phase. The mobile phase was attained the optimal separation of tacrine and curcumin. The internal standard, i.e., tenofovir was not interfered with the other components in plasma samples.

\section{HPLC method validation}

Specificity and Sensitivity

Chromatograms of tacrine, curcumin, and tenofovir (internal standard) were obtained from rat plasma extracts of the drugs were represented in Fig. 1. The endogenous compound peaks were not interfered with the detection of tacrine, curcumin, and I.S (tenofovir) at their respective retention times (tacrine $R_{t}=4.67 \mathrm{~min}$, curcumin $R_{t}=9.19 \mathrm{~min}$, and I.S (tenofovir) $\mathrm{R}_{\mathrm{t}}=7.01 \mathrm{~min}$ ) in blank. LOD was found to be 0.193 and 0.217 and LOQ was found to be 0.586 and 0.660 for tacrine and curcumin, respectively, and the corresponding results are presented in Table 1.

Table 1: LOD and quantitation

\begin{tabular}{lll}
\hline Parameter & Tacrine & Curcumin \\
\hline LOD & 0.193591 & 0.217919 \\
LOQ & 0.586639 & 0.660361 \\
\hline LOD: Limit of detection LOQ: Limit
\end{tabular}


Linearity of calibration curve

The calibration curves of tacrine and curcumin were found to be linear over the concentration range of 200-4000 and 1000-5000 ng/mL, respectively. Correlation coefficient of tacrine and curcumin was 0.999 and 0.998, respectively. The results are shown in Figs. 2 and 3 and Table 2 .

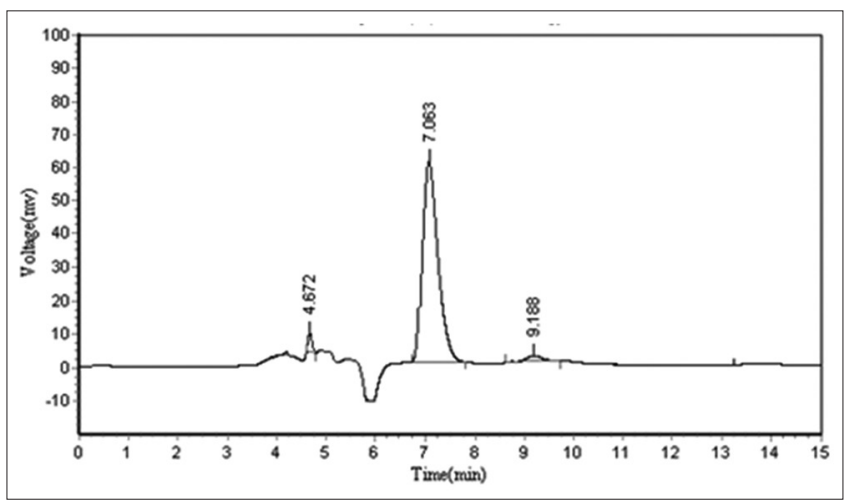

Fig. 1: Chromatogram of tacrine and curcumin with IS (tenofovir)

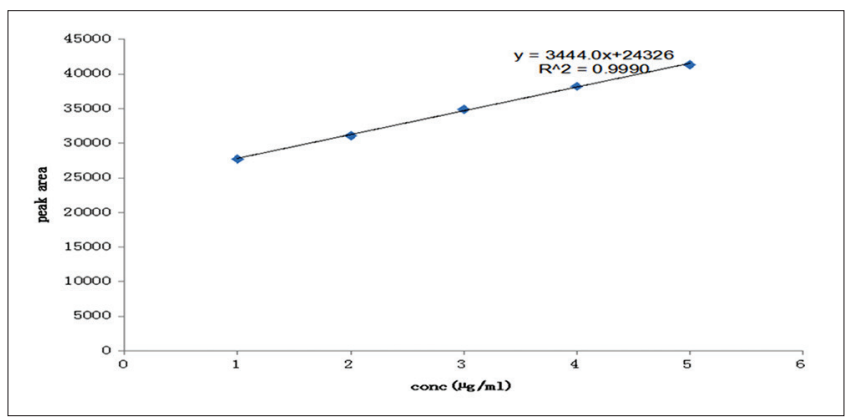

Fig. 2: Calibration curve for tacrine

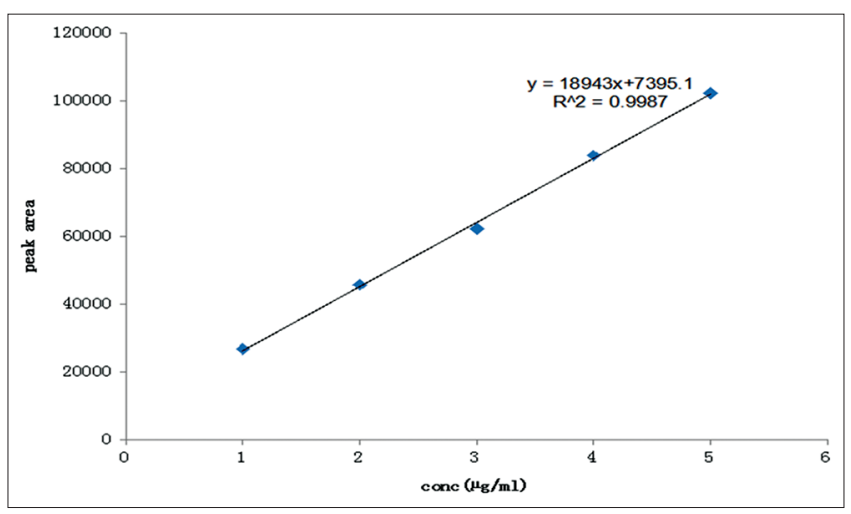

Fig. 3: Calibration curve for curcumin

\section{Precision and accuracy}

Table 3 shows the data of intra- and inter-day precision and accuracy. Accuracy of 200, 400, and $1500 \mathrm{ng} / \mathrm{mL}$ was found to be $99.1,96.3$, and 99.1 for tacrine, and accuracy of 1000,2000 , and $3000 \mathrm{ng} / \mathrm{mL}$ was found to be $99.1,98.43$, and 98.74 for curcumin. The intra- and interday precisions ( $\%$ deviation) were falling within $< \pm 2 \%$ for the LOQ. The intra- and inter-day assay precision (CV) ranged from 1.56 to 0.21 and 1.8 to $0.85 \%$ for tacrine and curcumin, respectively. These results indicated that the present assay has very good accuracy and precision. The results are shown in Tables 3-5.

\section{Robustness}

By changing the wavelength (246 and $236 \mathrm{~nm}$ ) and flow rate $(0.9$ and $1.1 \mathrm{~mL} / \mathrm{min}$ ) of the mobile phase, the robustness was studied. The results are shown in Tables 6 and 7. The results were satisfactory.

\section{Ruggedness}

The operating conditions were changed during the experiment with a standard solution of the drug substance. The conditions were changed and examined, including different operator, different instrument, different laboratory, changing source of reagent and solvent, and changing a new column.

System suitability parameters for curcumin and tacrine

These tests were performed to check the suitability of the chromatographic system for the intended analysis. The tests were basically related to the equipment performance, analytical operations, and sample constituents. And the evaluation results were shown in Table 8.

Factors that may affect chromatographic behavior include the following: Mobile phase related, including the composition of solvents, ionic strength, temperature, and apparent $\mathrm{pH}$; stationary phase related, including type of chromatographic support (particle-based or monolithic) particle or macropore size, porosity, and specific surface area; and operational related, including flow rate, column dimensions, column temperature, and pressure.

\section{Pharmacokinetic data}

The concentration of tacrine and curcumin in extracted plasma was determined, and the graph was plotted by taking average concentration $(\mathrm{ng} / \mathrm{mL})$ values of drug in plasma samples on Y-axis and corresponding time in hours on X-axis. The pharmacokinetic data of tacrine and curcumin are depicted in Tables 9-13. The influence of concomitant administration of curcumin on tacrine disposition was demonstrated by the serum concentration profiles as shown in Figs. 4-10, and the pharmacokinetic parameters are shown in Table 14.

Both curcumin and tacrine reached maximum concentration after $3 \mathrm{~h}$ of oral administration. The mean concentration of tacrine and curcumin was found to be $56.65 \pm 1.61$ and $49.91 \pm 5.87 \mathrm{ng} / \mathrm{mL}$. Surprisingly, the mean $\mathrm{C}_{\max }$ of tacrine was improved to $73.42 \pm 2.16 \mathrm{ng} / \mathrm{mL}$, when these two were administered concomitantly. The AUC values obtained in the oral administration of tacrine and curcumin were 742.78 and $672.35 \mathrm{ng} . \mathrm{h} / \mathrm{mL}$, respectively, whereas the $\mathrm{t}_{1 / 2}$ was 1.09 and $0.98 \mathrm{~h}^{-1}$.

Table 2: Linearity data for curcumin and tacrine

\begin{tabular}{|c|c|c|c|c|}
\hline \multirow[t]{2}{*}{ S. No } & \multicolumn{2}{|l|}{ Curcumin } & \multicolumn{2}{|l|}{ Tacrine } \\
\hline & Concentration $(\mathrm{ng} / \mathrm{mL})$ & Peak area & Concentration (ng/mL) & Peak area \\
\hline 1 & 1000 & 26734.8 & 200 & 27699.75 \\
\hline 3 & 3000 & 62312.59 & 400 & 34900.55 \\
\hline 4 & 4000 & 83914.91 & 1500 & 38219 \\
\hline 5 & 5000 & 102384.2 & 4000 & 41363.2 \\
\hline \multirow[t]{3}{*}{ Statistical analysis } & \multicolumn{2}{|l|}{ Slope: 18943} & \multicolumn{2}{|l|}{ Slope: 3444} \\
\hline & \multicolumn{2}{|l|}{ Y-intercept: 7395.1} & \multicolumn{2}{|l|}{ Y-intercept: 24326} \\
\hline & \multicolumn{2}{|c|}{ Correlation coefficient $\left(\mathrm{R}^{2}\right): 0.998$} & \multicolumn{2}{|c|}{ correlation coefficient $\left(\mathrm{R}^{2}\right): 0.999$} \\
\hline
\end{tabular}


Table 3: Precision data

\begin{tabular}{llll}
\hline Intraday & & & \\
\hline Concentration $\mathbf{( n g / m L )}$ & Mean & SD & \%RSD \\
\hline 200 & 15164.7 & 125.21 & 0.82 \\
400 & 39035.62 & 82.18 & 0.21 \\
1500 & 57539.48 & 901.74 & 1.56 \\
Interday & & & \\
\hline Concentration $(\mathbf{n g} / \mathbf{m L})$ & Mean & SD & \%RSD \\
\hline 200 & 15136.21 & 142.5 & 0.94 \\
400 & 38919.23 & 338.51 & 0.85 \\
1500 & 58051.36 & 1098.5 & 1.8 \\
\hline
\end{tabular}

Table 4: Accuracy study data for tacrine

\begin{tabular}{lll}
\hline Accuracy & & \\
\hline Concentration (ng/mL) & *Mean & \%Recovery \\
\hline 200 & 197.38 & 99.1 \\
400 & 392.89 & 96.3 \\
1500 & 1493.57 & 99.1 \\
\hline
\end{tabular}

Table 5: Accuracy study data for curcumin

\begin{tabular}{lll}
\hline Accuracy & & \\
\hline Concentration $\mathbf{( n g} / \mathbf{m L})$ & *Mean & \%Recovery \\
\hline 1000 & 196.74 & 99.1 \\
2000 & 391.25 & 98.43 \\
3000 & 1489.37 & 98.74 \\
\hline
\end{tabular}

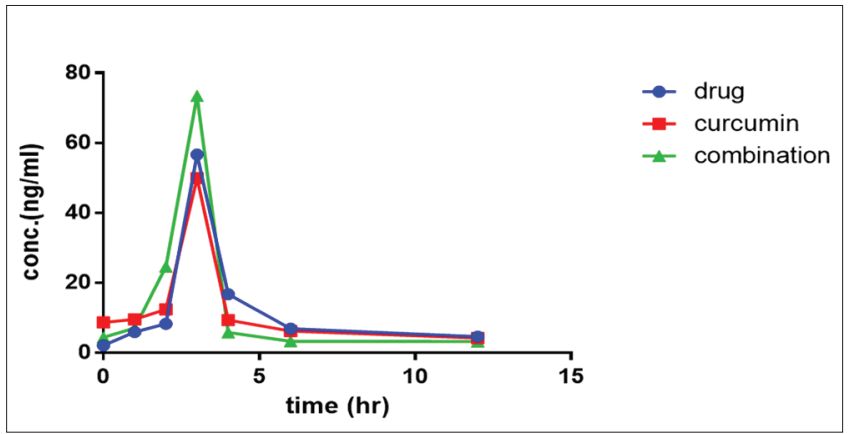

Fig. 4: Time versus concentration profile of tacrine and curcumin single day

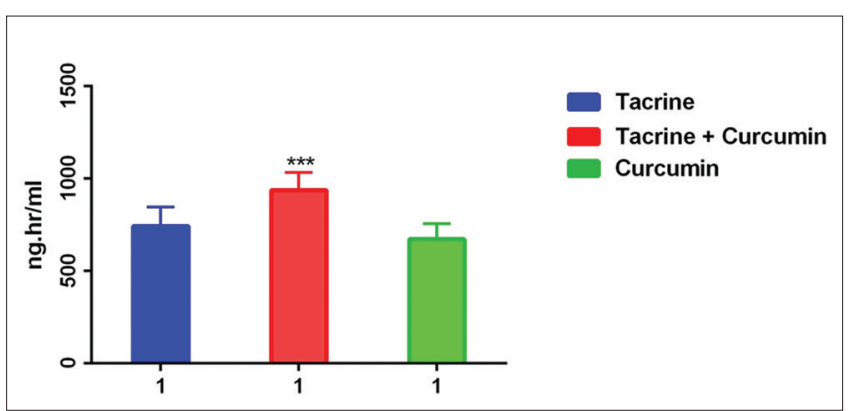

Fig. 5: AUC of tacrine and curcumin after single day oral administration $\left({ }^{*} \mathbf{p}<0.05 ;{ }^{* *} \mathbf{p}<0.01 ;{ }^{* * *} \mathbf{p}<0.001\right)$ when compared with the tacrine and curcumin alone by using one-way ANOVA followed by Dunnett's test

Table 6: Robustness (flow rate)

\begin{tabular}{|c|c|c|c|c|c|}
\hline Flow rate & Drug & Theoretical concentration $\mathrm{ng} / \mathrm{mL}$ & Mean (Peak area) & Rt value & $\%$ RSD \\
\hline \multirow{4}{*}{$0.9 \mathrm{~mL} / \mathrm{min}$} & Tacrine & 200 & 12593.652 & 4.67 & 0.95 \\
\hline & & 400 & 20165.781 & 4.68 & 1.02 \\
\hline & Curcumin & 1000 & 19568.652 & 9.18 & 1.16 \\
\hline & & 2000 & 149100.422 & 9.18 & 1.09 \\
\hline \multirow[t]{3}{*}{$1.1 \mathrm{~mL} / \mathrm{min}$} & Tacrine & 200 & 12581.622 & 4.71 & 1.04 \\
\hline & & 400 & 20162.521 & 4.70 & 1.5 \\
\hline & Curcumin & 1000 & 19668.652 & 9.24 & 1.38 \\
\hline
\end{tabular}

Table 7: Robustness (wavelength)

\begin{tabular}{|c|c|c|c|c|c|}
\hline Wavelength & Drug & Theoretical concentration $\mu \mathrm{g} / \mathrm{mL}$ & Mean (peak area) & $R_{t}$ value & $\%$ RSD \\
\hline \multirow{4}{*}{$246 \mathrm{~nm}$} & \multirow[t]{2}{*}{ Tacrine } & 200 & 12581.622 & 4.68 & 1.25 \\
\hline & & 400 & 20162.521 & 4.67 & 0.97 \\
\hline & \multirow[t]{2}{*}{ Curcumin } & 1000 & 19668.652 & 9.36 & 1.29 \\
\hline & & 2000 & 149909.422 & 9.39 & 1.41 \\
\hline \multirow{3}{*}{$236 \mathrm{~nm}$} & \multirow{2}{*}{ Tacrine } & 200 & 12593.652 & 4.68 & 1.32 \\
\hline & & 400 & 20165.781 & 4.68 & 1.26 \\
\hline & Curcumin & 1000 & 19568.652 & 9.29 & 1.09 \\
\hline
\end{tabular}

Table 8: System suitability parameters

\begin{tabular}{|c|c|c|c|c|c|c|c|c|c|}
\hline \multicolumn{2}{|l|}{ Replicate injections } & \multicolumn{4}{|c|}{ Curcumin } & \multicolumn{4}{|c|}{ Tacrine } \\
\hline & & $\mathbf{R}$ & Peak area & $\mathbf{N}$ & $\mathbf{T}$ & $\mathbf{R}$ & Peak area & $\mathbf{N}$ & $\mathbf{T}$ \\
\hline 1 & & 4.67 & 5684004 & 3894.2 & 2.068 & 9.18 & 1344089 & 132771 & 1.793 \\
\hline 2 & & 4.66 & 5679100 & 3771.3 & 2.041 & 9.08 & 1344110 & 1327101 & 1.802 \\
\hline 3 & & 4.67 & 5714319 & 3821.4 & 2.059 & 9.06 & 1343969 & 133660 & 1.811 \\
\hline 4 & & 4.65 & 5809930 & 3915.0 & 2.04 & 9.21 & 1344210 & 134917 & 1.786 \\
\hline 5 & & 4.64 & 5871163 & 3891.3 & 2.01 & 9.16 & 1344036 & 1352121 & 1.719 \\
\hline 6 & & 4.67 & 5670119 & 3796.2 & 1.97 & 9.19 & 1343987 & 1357432 & 1.788 \\
\hline \multirow[t]{3}{*}{ Statistical analysis } & Mean & 4.66 & 5738049 & 3848.21 & 2.0313 & 9.14 & 1344067 & 1341688 & 1.7831 \\
\hline & SD & 0.0116 & 83.05 & 59.627 & 0.036 & 0.0453 & 8.914 & 130.13 & 0.032 \\
\hline & $\%$ RSD & 0.19 & 1.44 & 1.54 & 1.77 & 0.45 & 0.006 & 0.969 & 1.794 \\
\hline
\end{tabular}


Table 9: Concentration and time profile of tacrine after oral administration on single day

\begin{tabular}{|c|c|c|c|c|c|c|}
\hline Time (h) & Animal 1 & Animal 2 & Animal 3 & Animal 4 & Mean & SD \\
\hline 0 & 0 & 0 & 0 & 0 & 0 & 0 \\
\hline 1 & 6.943 & 7.258 & 8.521 & 8.836 & 7.89 & 0.232 \\
\hline 2 & 19.078 & 19.945 & 23.414 & 24.281 & 21.68 & 0.638 \\
\hline 3 & 49.85 & 52.11 & 61.182 & 63.448 & 56.65 & 1.611 \\
\hline 4 & 29.881 & 24.545 & 28.814 & 23.478 & 26.68 & 0.785 \\
\hline 6 & 7.840 & 9.622 & 9.979 & 8.197 & 8.91 & 0.262 \\
\hline 12 & 5.129 & 4.213 & 4.946 & 4.030 & 4.58 & 0.134 \\
\hline
\end{tabular}

Table 10: Concentration and time profile of curcumin after oral administration on single day

\begin{tabular}{|c|c|c|c|c|c|c|}
\hline Time (h) & Animal 1 & Animal 2 & Animal 3 & Animal 4 & Mean & SD \\
\hline 0 & 0 & 0 & 0 & 0 & 0 & 0 \\
\hline 1 & 11.40 & 13.88 & 10.912 & 13.284 & 12.4 & 1.43 \\
\hline 2 & 19.71 & 24.19 & 25.08 & 20.60 & 22.4 & 2.63 \\
\hline 3 & 45.91 & 55.89 & 43.92 & 53.90 & 49.91 & 5.87 \\
\hline 4 & 21.85 & 17.94 & 21.070 & 17.168 & 19.51 & 2.30 \\
\hline 6 & 9.18 & 7.54 & 8.85 & 7.21 & 8.2 & 0.96 \\
\hline 12 & 3.66 & 3.83 & 4.50 & 4.67 & 4.17 & 0.49 \\
\hline
\end{tabular}

Table 11: Concentration and time profile of tacrine and curcumin after oral administration on single day

\begin{tabular}{|c|c|c|c|c|c|c|}
\hline Time (h) & Animal 1 & Animal 2 & Animal 3 & Animal 4 & Mean & SD \\
\hline 0 & 0 & 0 & 0 & 0 & 0 & 0 \\
\hline 1 & 14.517 & 13.886 & 17.673 & 17.042 & 15.78 & 0.564 \\
\hline 2 & 22.595 & 27.507 & 21.612 & 26.524 & 24.56 & 0.722 \\
\hline 3 & 67.546 & 64.609 & 79.293 & 82.230 & 73.42 & 2.161 \\
\hline 4 & 36.396 & 46.323 & 44.668 & 38.051 & 41.36 & 1.217 \\
\hline 6 & 19.084 & 15.676 & 14.995 & 18.403 & 17.04 & 0.501 \\
\hline 12 & 3.836 & 4.011 & 4.708 & 4.883 & 4.36 & 0.128 \\
\hline
\end{tabular}

Table 12: Pharmacokinetic data of tacrine after single day administration

\begin{tabular}{llllllll}
\hline Animal & $\mathbf{C}_{\max }(\mathbf{n g} / \mathbf{m L})$ & $\mathbf{T}_{\max } \mathbf{( h )}$ & AUC $(\mathbf{n g} . \mathbf{h} / \mathbf{m L})$ & $\mathbf{t}_{\mathbf{y}_{\mathbf{2}}}\left(\mathbf{h} \mathbf{h}^{-1}\right)$ & $\mathbf{M R T}(\mathbf{h})$ & $\mathbf{C l}(\mathbf{L} / \mathbf{h})$ & $\mathbf{V}_{\mathbf{d}}(\mathbf{L})$ \\
\hline 1 & 49.85 & 3 & 626.537 & 0.854 & 1.347 & 0.091 & 1.33 \\
2 & 52.11 & 3 & 711.682 & 1.041 & 1.557 & 0.085 & 1.472 \\
3 & 61.18 & 3 & 875.511 & 1.431 & 2.255 & 0.098 & 1.956 \\
4 & 56.65 & 3 & 757.429 & 1.044 & 1.598 & 0.112 & 1.644 \\
Mean & 56.65 & 3 & 742.7898 & 1.0925 & 1.68925 & 0.0965 & 1.6005 \\
SD & 1.61 & 0 & 103.7812 & 0.242535 & 0.392863 & 0.011619 & 0.26954 \\
\hline
\end{tabular}

Table 13: Pharmacokinetic data of curcumin after single day administration

\begin{tabular}{|c|c|c|c|c|c|c|c|}
\hline Animal & $\mathrm{C}_{\max }(\mathrm{ng} / \mathrm{mL})$ & $\mathbf{T}_{\max }(\mathbf{h})$ & AUC (ng.h/mL) & $\mathbf{t}_{1 / 2}\left(\mathbf{h}^{-1}\right)$ & MRT (h) & $\mathrm{Cl}(\mathrm{L} / \mathrm{h})$ & $V_{d}(L)$ \\
\hline 1 & 45.91 & 3 & 576.960 & 0.787 & 1.241 & 0.083 & 1.216 \\
\hline 2 & 55.89 & 3 & 763.30 & 1.116 & 1.669 & 0.091 & 1.576 \\
\hline 3 & 43.92 & 3 & 628.492 & 1.027 & 1.618 & 0.070 & 1.397 \\
\hline 4 & 53.90 & 3 & 720.661 & 0.993 & 1.520 & 0.106 & 1.555 \\
\hline Mean & 49.91 & 3 & 672.3533 & 0.98075 & 1.512 & 0.0875 & 1.436 \\
\hline SD & 5.87 & 0 & 84.90903 & 0.139189 & 0.190954 & 0.015067 & 0.167015 \\
\hline
\end{tabular}

Table 14: Pharmacokinetic data of tacrine and curcumin after single day administration

\begin{tabular}{|c|c|c|c|c|c|c|c|}
\hline Animal & $C_{\max }(\mathrm{ng} / \mathrm{mL})$ & $\mathbf{T}_{\max }(\mathbf{h})$ & AUC (ng.h/mL) & $\mathbf{t}_{1 / 2}\left(\mathbf{h}^{-1}\right)$ & MRT (h) & $\mathrm{Cl}(\mathrm{L} / \mathrm{h})$ & $V_{d}(L)$ \\
\hline 1 & 67.546 & 3 & 852.154 & 0.881 & 1.435 & 0.0921 & 1.189 \\
\hline 2 & 64.609 & 3 & 858.53 & 0.979 & 1.579 & 0.106 & 1.403 \\
\hline 3 & 79.293 & 3 & 1009.255 & 1.270 & 1.878 & 0.104 & 1.668 \\
\hline 4 & 82.230 & 3 & 1030.32 & 1.085 & 1.793 & 0.110 & 1.778 \\
\hline Mean & 73.42 & 3 & 937.5648 & 1.05375 & 1.67125 & 0.103025 & 1.5095 \\
\hline SD & 2.161 & 0 & 95.36686 & 0.166504 & 0.201571 & 0.007699 & 0.265378 \\
\hline
\end{tabular}

When these two were given concomitantly, the AUC of tacrine was found to be $937.56 \mathrm{ng} . \mathrm{h} / \mathrm{mL}$ and the $\mathrm{t}_{1 / 2}$ was $1.05 \mathrm{~h}^{-1}$. MRT was not altered by curcumin (tacrine $-1.68 \mathrm{~h}$ and tacrine and curcumin - $1.67 \mathrm{~h}$ ). The clearance of tacrine alone was $0.09 \mathrm{~L} / \mathrm{h}$ and when it was given along with curcumin was $0.10 \mathrm{~L} / \mathrm{h}$, whereas the volume of distribution was 1.60 and $1.50 \mathrm{~L}$ for tacrine alone and in combination, respectively. 


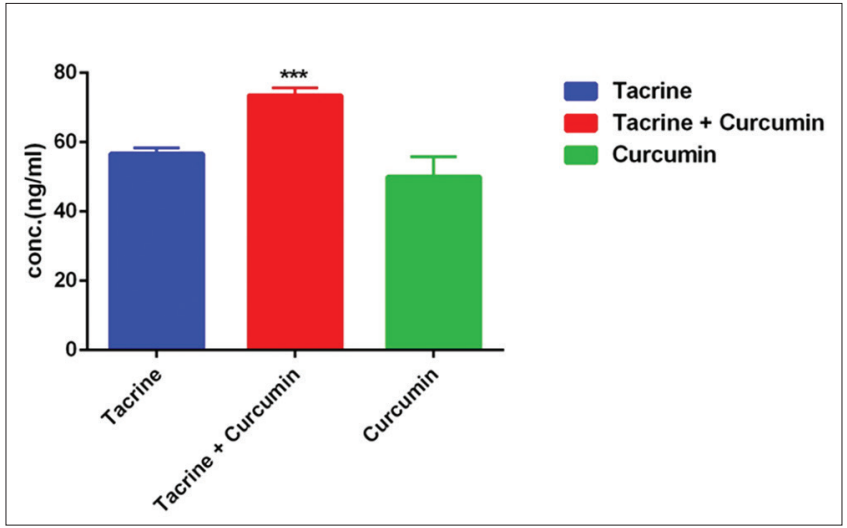

Fig. 6: $\mathrm{C}_{\max }$ of tacrine and curcumin after single day oral administration. $\left({ }^{*} \mathbf{p}<0.05 ;{ }^{* *} \mathbf{p}<0.01 ;{ }^{* * *} \mathbf{p}<0.001\right)$ when compared with the tacrine and curcumin alone using one-way ANOVA followed by Dunnett's test

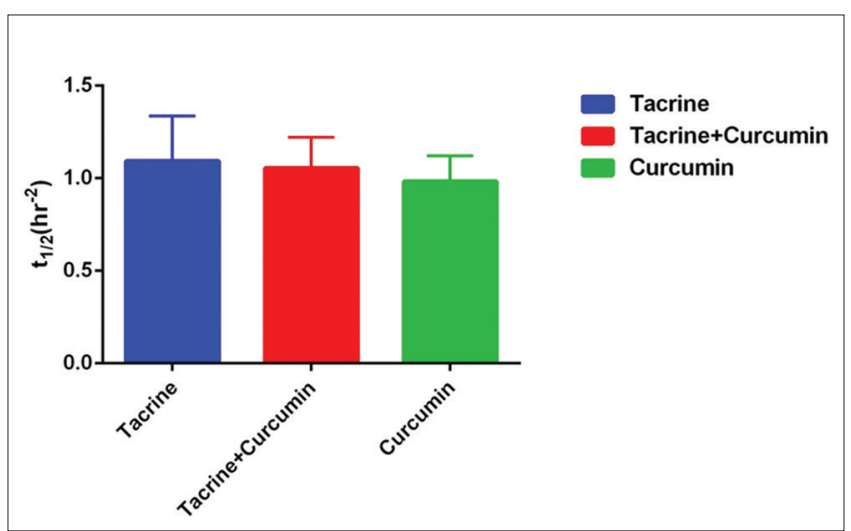

Fig. 7: Half-life of tacrine and curcumin after single day oral administration

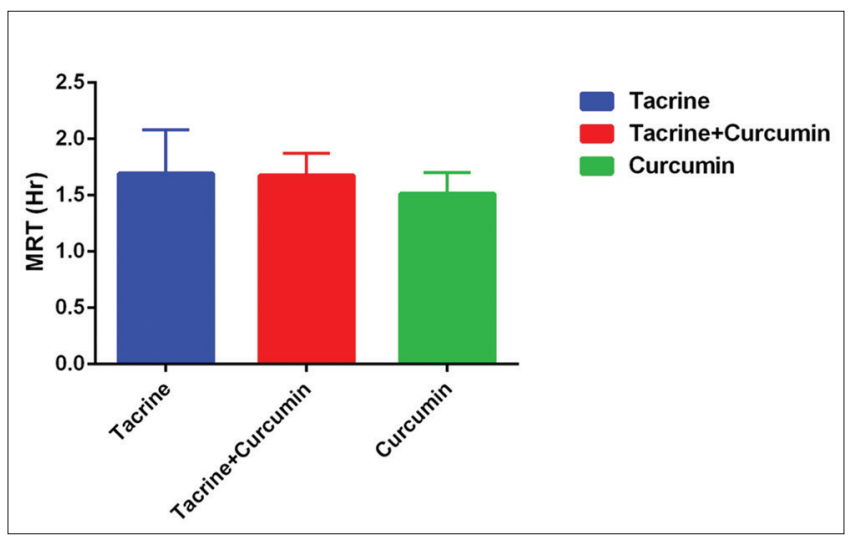

Fig. 8: MRT of tacrine and curcumin after single day oral administration

Statistical analysis indicated that the differences in $\mathrm{C}_{\max }$ and AUC between two treatments were significant. Curcumin increased both the parameters that indicate that the curcumin would improve the absorption of tacrine. Other pharmacokinetic parameters were not significantly affected by coadministration of curcumin. Although CYP $1 \mathrm{~A} 2$ is the main isozymes thought to catalyze tacrine metabolism and curcumin demonstrated potent inhibition on rat liver CYP $1 \mathrm{~A} 1 / 1 \mathrm{~A} 2$, our present study indicated that the effects of concomitant administration of curcumin on tacrine systemic clearance were generally negligible. This could be due to the poor absorption of curcumin from the gut.

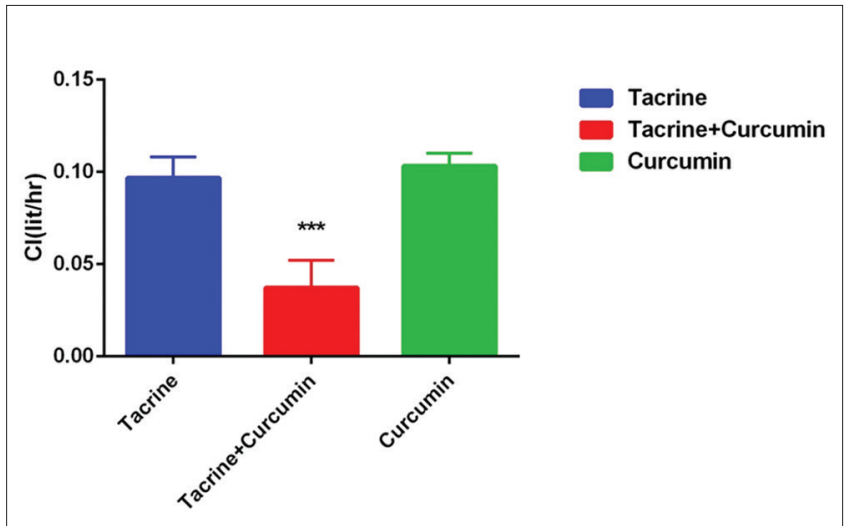

Fig. 9: Clearance of tacrine and curcumin after single day oral administration. $\left({ }^{*} \mathbf{p}<0.05 ;{ }^{* *} \mathrm{p}<0.01 ;{ }^{* * *} \mathrm{p}<0.001\right)$ when compared with the tacrine and curcumin alone using one-way ANOVA followed by Dunnett's test

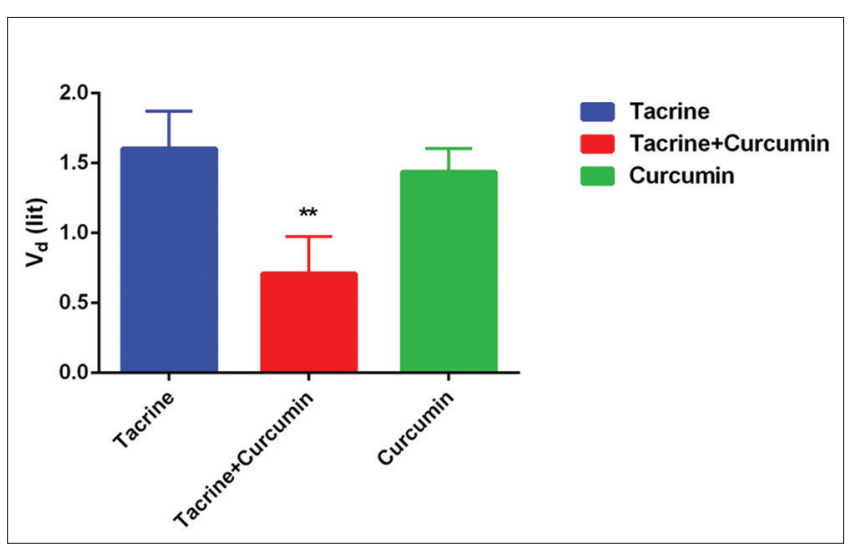

Fig. 10: Vd of tacrine and curcumin after single day oral administration.

\section{CONCLUSION}

The present investigation was designed based on the hypothesis of curcumin and tacrine simultaneous administration can minimize the toxicity of tacrine and improves its bioavailabity along with its biological activities may improve the therapeutic approach for the treatment of AD. Hence, an attempt was made to study the pharmacokinetic interaction of curcumin and tacrine when they administered simultaneously with the help of cost-effective RP-HPLC method. From the present study, we can conclude that there is a significant effect of curcumin on tacrine pharmacokinetic parameters which is a desirable effect. However, an extensive research is needed to prove the effect of curcumin on chronic treatment.

\section{ACKNOWLEDGMENT}

Authors would like to thank Director, Vaagdevi College of Pharmacy, for providing facilities. ARR wish to thank DST for financial assistance (SR/ FT/CS-114/2010).

\section{AUTHOR'S CONTRIBUTION}

ARR, PK, and GT were contributed for the analytical and pharmacological part of the manuscript. UK, BS, and BM were contributed to the statistical calculations of the present work.

\section{CONFLICTS OF INTEREST}

The authors declare that there are no conflicts of interest. 


\section{Graphical Abstract}

A simple, precise, accurate, and cost-effective reversed-phase HPLC (RP-HPLC) method was developed for simultaneous determination of curcumin and tacrine and also to estimate the pharmacokinetic interactions of curcumin on tacrine.

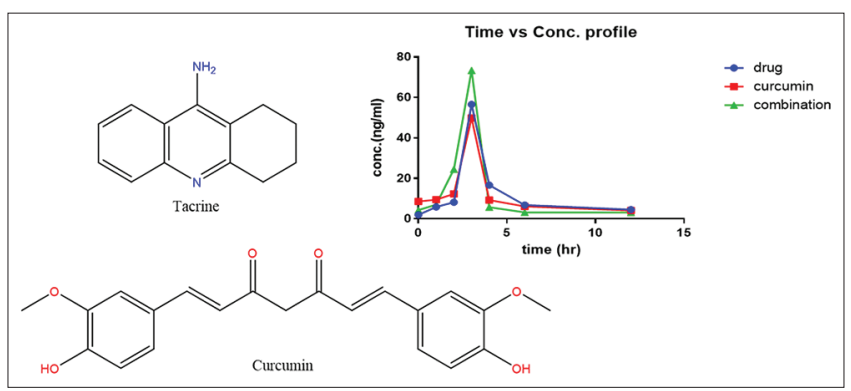

\section{REFERENCES}

1. Madden SP, Spaldin V. Clinical pharmacokinetics of tacrine. Clin Pharmacokinet 1995;28:449-57.

2. Korabecny FZ, Musilek K. Synthesis and in vitro evaluation of 7-methoxy-N-(pent-4-enyl)-1,2,3,4-tetrahydroacridin-9-amine-new tacrine derivate with cholinergic properties. Bioorg Med Chem Lett 2011;21:6563-6

3. Gupta SC, Kismali G. Curcumin, a component of turmeric: From farm to pharmacy. Bio Factors 2013;39:2-13

4. Pan MH, Huang TM. Biotransformation of curcumin through reduction and glucuronidation in mice. Drug Metab Disp 1999;27:486-94.

5. Vareed SK, Kakarala M. Pharmacokinetics of curcumin conjugate metabolites in healthy human subjects, cancer epidemiol. Biomarkers Prev 2008;17:1411-7.

6. Anand PK, Thomas SG. Biological activities of curcumin and its analogues (Congeners) made by man and mother nature. Biochem Pharmacol 2008:76:1590-611.

7. Jantarat C. Bioavailability enhancement techniques of herbal medicine: A case example of curcumin. Int J Pharm Pharm Sci 2013;5:493-500.

8. Basu NK, Kole L, Kubota S. Human UDP-glucuronosyltransferases show a typical metabolism of mycophenolic acid and inhibition by curcumin. Drug Metab Disp 2004;32:768-77.

9. Thapliyal RM. Inhibition of cytochrome P450 isozymes by curcumins in vitro and in vivo. Food Chem Toxicol 2001;39:541-7.

10. Zhang WL. Effects of spice constituents on P-glycoprotein-mediated transport and CYP3A4-mediated metabolism in vitro. Drug Metab Dispos 2008;36:1283-90.
11. Zhang WL, Tan TM. Impact of curcumin-induced changes in P-glycoprotein and CYP3A expression on the pharmacokinetics of peroral celiprolol and midazolam in rats. Drug Metab Dispos 2007;35:110-5.

12. Kiso YH, Suzuki Y, Watanabe N, Oshima Y. Antihepatotoxic principles of curcuma longa rhizomes. Planta Med 1983;49:185-7.

13. Venkatesan NA, Punithavathi D. Curcumin prevents adriamycin nephrotoxicity in rats. Br. J. Pharmacol 2000;129:231-24.

14. Ahmed TG. Inhibitory effect of curcuminoids on acetylcholinesterase activity and attenuation of scopolamine-induced amnesia may explain medicinal use of turmeric in alzheimer's disease. Pharmacol Biochem Behav 2009;91:554-9.

15. Yang FB, Lim GP. Curcumin inhibits formation of amyloid beta oligomers and fibrils, binds plaques, and reduces amyloid in vivo. J Biol Chem 2005;280:5892-901.

16. Shaikh VJ. Development and validation of a RP-HPLC method for the simultaneous determination of curcumin, piperine and camphor in an ayurvedic formulation. Int J Pharm Pharm Sci 2018;10:115.

17. Heath DD, Pruitt MA, Brenner DE. Curcumin in plasma and urine: Quantitation by high-performance liquid chromatography. J Chromatogr B Anal Technol Biomed Life Sci 2003;783:287-95.

18. Shankar PS, Umashankar D, Jonathan RD. A general HPLC-UV method for the quantitative determination of curcumin analogue containing the 1, 5-diaryl-3-oxo-1, 4-pentadienyl pharmacophore in rat biomatrices. J Chromatogr B Anal Technol Biomed Life Sci 2010;878:2796-802.

19. Dalapathi GV, Preshitha D. A versatile liquid chromatographic technique for pharmacokinetic estimation of curcumin in human plasma. J Chromatogr Sci 2014;52:872-9.

20. Hadwiger ME, Telting-Diaz M. Liquid chromatographic determination of tacrine and its metabolites in rat bile microdialysates. J Chromatogr B Biomed Appl 1994;655:235-41.

21. Hansen LL, Larsen JT. Determination of tacrine and its metabolites in human plasma and urine by high performance liquid chromatography and fluorescence detection. J Chromatogr B Biomed Sci Appl 1998;712: 183-91

22. James PA. Validation of Pharmaceutical Processes. Pennsylvania, USA: CRC Press; 2007.

23. Validation Of Analytical Procedures: Text And Methodology Q2(R1), In: The International Conference on Harmonisation of Technical Requirements for Registration of Pharmaceuticals for Human. USE; 2005. p. 1-17.

24. Ingkaninan $\mathrm{K}$, de Best CM, van der Heijden R, Hofte AJ, Karabatak B, Irth $\mathrm{H}$, et al. High-performance liquid chromatography with online coupled UV, mass spectrometric and biochemical detection for identification of acetylcholinesterase inhibitors from natural products. J Chromatogr A 2000;872:61-73.

25. Szymanski P, Karpinski A. Synthesis, biological activity and HPLC validation of 1,2,3,4- tetrahydroacridine derivatives as acetylcholinesterase inhibitors. Eur J Med Chem 2011;46:3250-7. 